\title{
Physiologic risk assessment in stable ischemic heart disease: still superior to the anatomic angiographic approach
}

\author{
Alessia Gimelli, MD, Paolo Marzullo, MD, FESC, and Daniele Rovai, MD, FESC
}

In patients with ischemic heart disease (IHD), a functional risk assessment based on non-invasive tests may conflict with a health care policy oriented toward cost containment and direct reperfusion delivery. In this respect, a survey of the European Society of Cardiology has shown that noninvasive tests are underutilized, with wide variability between different countries, ${ }^{1}$ so that several patients without significant IHD directly undergo invasive coronary angiography. On the other hand, coronary lesions detected by coronary angiography often are revascularized even without the evidence that myocardial blood supply or mechanical function is altered. ${ }^{2}$ This "anatomically oriented" invasive approach may negatively impact patient management, with consequent suboptimal medical treatment, inappropriate revascularizations, additional risks, and increased health costs.

To investigate the prognostic power of gated SPECT in current practice, we recently studied a cohort of 676 consecutive patients admitted for known or suspected IHD. ${ }^{3}$ Each patient underwent a complete diagnostic work-up that included clinical evaluation, laboratory tests, 12-lead electrocardiogram, two-dimensional echocardiography, stress/rest gated SPECT, and coronary angiography. During follow-up (median, 37 months), 24 patients died from cardiac causes and 19 had a nonfatal myocardial infarction (MI). Several variables were independent predictors of event-free survival (cardiac death and non-fatal MI) in the different phases of diagnostic work-up. When the above predictors were tested together, summed rest score (SRS), summed difference score (SDS), serum creatinine, and LDL/HDL cholesterol were the only final independent predictors of event-free survival (Table 1). The results of this study lead us to

From the CNR Clinical Physiology Institute \& Gabriele Monasterio Foundation, Pisa, Italy.

Received for publication Jun 12, 2009; final revision accepted Jun 17, 2009.

Reprint requests: Alessia Gimelli, MD, CNR Clinical Physiology Institute \& Gabriele Monasterio Foundation, Via Moruzzi, 1, 56124 Pisa, Italy; gimelli@ifc.cnr.it.

J Nucl Cardiol 2009;16:697-700.

$1071-3581 / \$ 34.00$

Copyright (C) 2009 by the American Society of Nuclear Cardiology. doi:10.1007/s12350-009-9116-7 make some considerations on risk stratification in stable IHD.

\section{FUNCTIONAL RISK ASSESSMENT VS INVASIVE CORONARY ANGIOGRAPHY}

The prognostic power of angiographic coronary anatomy has been definitively established. In the CASS registry, ${ }^{4}$ the 12 -year survival rate of medically treated patients with no significant coronary lesions was $91 \%$, compared with $74 \%, 59 \%$, and $50 \%$ for patients with one, two-, and three-vessel disease. Survival rate is known to further decrease in the presence of left main coronary artery disease and severe proximal left anterior descending stenosis. ${ }^{5}$ To predict patient survival, we used an angiographic semi-quantitative score, which takes into account the number of stenotic coronary arteries, the location of coronary stenoses (proximal, middle, or distal), and the degree of luminal diameter reduction (using a $50 \%$ and $70 \%$ coronary stenosis threshold). As expected, this score was an independent predictor of event-free survival. However, the prognostic impact of this score disappeared once gated SPECT variables were included into the model. ${ }^{3}$

The notion that the prognostic impact of functional risk assessment is superior to angiography is not novel. In patients with defined coronary artery disease, exercise variables primarily relating to the functional state are known to provide incremental prognostic information over coronary anatomy. ${ }^{6}$ The treadmill score also adds independent prognostic information to that provided by clinical data, coronary arteriography, and left ventricular (LV) ejection fraction. ${ }^{7}$ The predictive power of clinical data also is strengthened by adding the results of dobutamine echocardiography ${ }^{8}$ and, to a minor degree, coronary anatomy data. In a group of patients who underwent stress echocardiography with dipyridamole or dobutamine, and who underwent coronary angiography within a year without an intervening procedure, coronary angiography parameters did not add significant predictive power to the model compared with stress echocardiographic variables. ${ }^{9}$ As for nuclear cardiology, the superiority of myocardial perfusion imaging compared with coronary angiography in risk stratification of 
Table 1. Independent predictors of event-free survival using multivariate analysis, considering all stages of diagnostic workup

\begin{tabular}{lcccc}
\hline Variable & HR & $\mathbf{9 5 \%}$ CI & $\boldsymbol{\chi}^{\mathbf{2}}$ & $\boldsymbol{P}$ value \\
\hline SRS & 1.16 & $1.08-1.25$ & 16.43 & .0001 \\
SDS & 1.15 & $1.03-1.27$ & 6.5 & .0108 \\
$\begin{array}{l}\text { Creatinine } \\
\quad \text { level }\end{array}$ & 2.51 & $1.18-4.79$ & 5.54 & .0186 \\
$\begin{array}{l}\text { LDL/HDL } \\
\quad \text { cholesterol } \\
\text { level }\end{array}$ & 1.53 & $1.06-2.16$ & 5.23 & .0222 \\
\hline
\end{tabular}

patients with IHD is also well known. In 1992, Pollock et al demonstrated that myocardial perfusion is superior to coronary angiography in risk stratification of IHD patients ${ }^{10}$; at variance with our study, these authors used 201-Tl and static planar imaging. In a series of 316 medically treated patients, Iskandrian et $\mathrm{al}^{11}$ showed the independent and incremental prognostic information of exercise SPECT thallium imaging even when catheterization data are available. All of these evidences definitively underline the superiority of functional risk stratification compared with an approach based solely on angiographic coronary anatomy.

Past and present observations can be partly explained by the limitations of coronary angiography, which has limited sensitivity compared with necropsy studies ${ }^{12}$ and intravascular ultrasound investigations. ${ }^{13}$ Furthermore, the identification of significant lesions may be confounded by coronary remodeling and by the extraluminal location of some plaques. ${ }^{14}$ Finally, coronary angiography gives no information on coronary microvascular dysfunction, increasingly recognized as independent determinant of impaired blood flow, disease progression, and adverse prognosis. ${ }^{15}$

\section{FUNCTIONAL RISK ASSESSMENT VS NONINVASIVE CORONARY ANGIOGRAPHY}

The prognostic value of coronary artery calcium (CAC) has been consistently demonstrated in large series of patients. ${ }^{16-18}$ Current evidence also suggests that the use of CAC is independently predictive of outcome over and above traditional cardiac risk factors. Concerning functional risk assessment, CAC scores are predictive of a higher likelihood of ischemia on PET myocardial perfusion imaging. ${ }^{19}$ More importantly, patients with and without ischemia on PET perfusion imaging exhibit a stepwise increase in their risk of cardiac events with increasing calcium scores. These findings suggest that imaging approaches that combine quantitative information on the anatomic burden of IHD with its physiological consequences offer improved risk stratification compared with conventional approaches that use myocardial perfusion alone. However, an independent and incremental prognostic value of CAC compared with clinical, electrocardiographic, laboratory, echocardiographic, and angiographic variables has not been demonstrated yet.

A similar consideration applies to computed tomography (CT) of the coronary arteries. Although the presence of obstructive coronary lesions at 64-slice CT angiography was a predictor of an adverse outcome compared with the patients with normal coronary arteries, ${ }^{20}$ an independent and incremental prognostic value of CT angiography compared with clinical and scintigraphic variables has not been demonstrated. To the best of our knowledge, two studies have been designed to test the impact of a combined anatomic and functional noninvasive imaging for detection and characterization of IHD: the EVINCI study in Europe and the SPARC trial in the United States of America. While we are waiting for the results of these two studies, patients' outcome in stable IHD should be estimated using the evidences so far collected.

\section{MYOCARDIAL PERFUSION IMAGING AND REVASCULARIZATION}

In the COURAGE trial, no difference in the composite of death, acute MI, and stroke was found between patients with stable IHD, objective evidence of ischemia, and significant coronary stenoses randomized to optimal medical therapy with or without percutaneous coronary intervention. ${ }^{21}$ The relationship between extent of myocardial ischemia at gated SPECT and coronary revascularization has been explored in a subset of patients enrolled in the COURAGE nuclear substudy. ${ }^{22}$ In these patients, the addition of percutaneous coronary intervention to optimal medical therapy resulted in more effective reduction of ischemia than optimal medical therapy alone; this greater reduction in ischemic burden was associated with improvements in angina class and less reliance on nitrate therapy for symptom relief. Moreover, patients with moderate to severe ischemia randomized to percutaneous coronary intervention plus optimal medical therapy more commonly experienced a significant reduction in ischemia at follow-up compared with those receiving optimal medical therapy (78\% vs $52 \%$ ). The results of the nuclear substudy suggest that gated SPECT could be utilized for the identification of patients who will benefit more from coronary revascularization. 


\section{PROPER DIAGNOSTIC WORK-UP}

In patients with stable IHD, myocardial perfusion imaging may be sometimes regarded as an unnecessary, or even redundant investigation. Our study shows that myocardial perfusion imaging at rest and after stress is still the best predictor of cardiac event-free survival, even compared with an extensive diagnostic workup. Specifically, when gated SPECT data were added to the clinical, laboratory, electrocardiographic, and echocardiographic variables, the prognostic stratification significantly improved; however, when coronary angiography was added to gated SPECT, prognostic stratification did not further improve (Figure 1, top panel). On the other hand, if the information provided by gated SPECT was made available after clinical, laboratory, electrocardiographic, echocardiographic, and angiographic variables, the prognostic stratification still improved significantly (Figure 1, lower panel). Thus, gated SPECT carries out prognostic information that is greater than that provided by coronary angiography. This observation suggests that the indications for myocardial perfusion
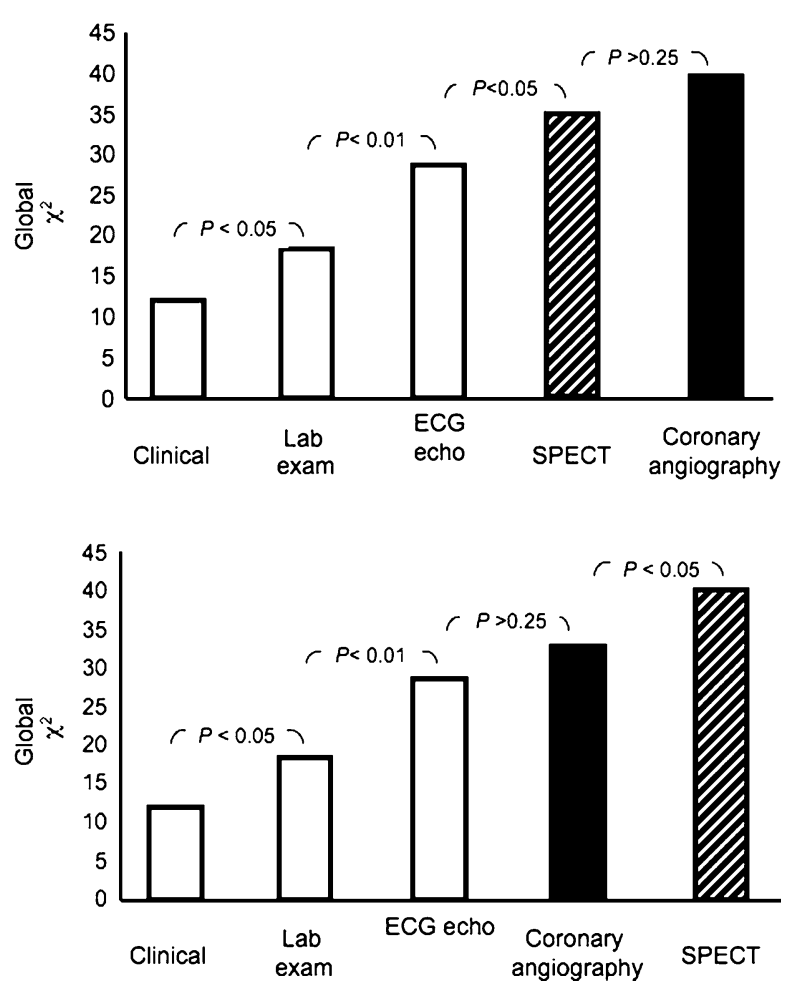

Figure 1. Incremental prognostic value during the diagnostic workup. In the upper panel, the information provided by stress/ rest gated SPECT is available after clinical examination, laboratory tests, electrocardiography, and echocardiography but before coronary angiography. In the lower panel, the information provided by gated SPECT is available after coronary angiography. Redrawn from Gimelli et al, J Nucl Med 2009;50:546-53. imaging in risk stratification of patients with known or suspected IHD should be broadened.

For several years, we have adopted the internal policy that the information regarding LV function, myocardial viability, and ischemia has to be available whenever possible before coronary angiography, as it was provided by gated SPECT in $92 \%$ of our study patients.

\section{CONCLUSIONS}

Several lines of evidence, collected with different approaches, demonstrate that a physiologic risk assessment is superior to an angiographically oriented approach in prognostic stratification of patients with stable IHD. In the authors view, stress/rest myocardial perfusion abnormalities should be known - whenever possible-before coronary angiography to guide decision making, provided that appropriateness and patient's risk/benefits ratio are correctly considered.

\section{References}

1. Breeman A, Hordijk-Trion M, Lenzen M, Hoeks S, Ottervanger JP, Bertrand ME, et al. Treatment decisions in stable coronary artery disease: Insights from the Euro Heart Survey on Coronary Revascularization. J Thorac Cardiovasc Surg 2006;132:1001-9.

2. Daly CA, Clemens F, Sendon JL, Tavazzi L, Boersma E, Danchin $\mathrm{N}$, et al. The clinical characteristics and investigations planned in patients with stable angina presenting to cardiologists in Europe: from the Euro Heart Survey of Stable Angina. Eur Heart J 2005;26:996-1010.

3. Gimelli A, Rossi G, Landi P, Marzullo P, Iervasi G, L'abbate A, et al. Stress/rest myocardial perfusion abnormalities by gated SPECT: Still the best predictor of cardiac events in stable ischemic heart disease. J Nucl Med 2009;50:546-53.

4. Emond M, Mock MB, Davis KB, Fisher LD, Holmes DR Jr, Chaitman BR, et al. Long-term survival of medically treated patients in the Coronary Artery Surgery Study (CASS) Registry. Circulation 1994;90:2645-57.

5. Mark DB, Nelson CL, Califf RM, Harrell FE Jr, Lee KL, Jones $\mathrm{RH}$, et al. Continuing evolution of therapy for coronary artery disease. Initial results from the era of coronary angioplasty. Circulation 1994;89:2015-25.

6. Weiner DA, Ryan TJ, McCabe CH, Chaitman BR, Sheffield LT, Ferguson JC, et al. Prognostic importance of a clinical profile and exercise test in medically treated patients with coronary artery disease. J Am Coll Cardiol 1984;3:772-9.

7. Mark DB, Hlatky MA, Harrell FE Jr, Lee KL, Califf RM, Pryor DB. Exercise treadmill score for predicting prognosis in coronary artery disease. Ann Intern Med 1987;106:793-800.

8. Marwick TH, Case C, Sawada S, Rimmerman C, Brenneman P, Kovacs R, et al. Prediction of mortality using dobutamine echocardiography. J Am Coll Cardiol 2001;37:754-60.

9. Sicari R, Pasanisi E, Venneri L, Landi P, Cortigiani C, Picano E, et al. Stress echo results predict mortality: A large-scale multicenter prospective international study. J Am Coll Cardiol 2003; 41:589-95. 
10. Pollock SG, Abbott RD, Boucher CA, Beller GA, Kaul S. Independent and incremental prognostic value of tests performed in hierarchical order to evaluate patients with suspected coronary artery disease: Validation of models based on these tests. Circulation 1992;85:237-48.

11. Iskandrian AS, Chae SC, Heo J, Stanberry CD, Wasserleben V, Cave V. Independent and incremental prognostic value of exercise single-photon emission computed tomographic (SPECT) thallium imaging in coronary artery disease. J Am Coll Cardiol 1993;22: 665-70.

12. Michalodimitrakis M, Mavroforou A, Giannoukas AD. Lessons learnt from the autopsies of 445 cases of sudden cardiac death in adults. Coron Artery Dis 2005;16:385-9.

13. Nissen SE. Pathobiology, not angiography, should guide management in acute coronary syndrome/non-ST-segment elevation myocardial infarction: The non-interventionist's perspective. J Am Coll Cardiol 2003;41:103S-12S.

14. Sipahi I, Tuzcu EM, Schoenhagen P, Nicholls SJ, Chen MS, Crowe $\mathrm{T}$, et al. Paradoxical increase in lumen size during progression of coronary atherosclerosis: Observations from the REVERSAL trial. Atherosclerosis 2006;189:229-35.

15. Neglia D, Michelassi C, Trivieri MG, Sambuceti G, Giorgetti A, Pratali L, et al. Prognostic role of myocardial blood flow impairment in idiopathic left ventricular dysfunction. Circulation 2002; 105:186-93.

16. Budoff MJ, Shaw LJ, Liu ST, Weinstein SR, Mosler TP, Tseng $\mathrm{PH}$, et al. Long-term prognosis associated with coronary calcification: Observations from a registry of 25,253 patients. J Am Coll Cardiol 2007;49:1860-70.
17. Taylor AJ, Bindeman J, Feuerstein I, Cao F, Brazaitis M, O'Malley PG. Coronary calcium independently predicts incident premature coronary heart disease over measured cardiovascular risk factors: Mean three-year outcomes in the Prospective Army Coronary Calcium (PACC) project. J Am Coll Cardiol 2005;46: 807-14.

18. Greenland P, LaBree L, Azen SP, Doherty TM, Detrano RC. Coronary artery calcium score combined with Framingham score for risk prediction in asymptomatic individuals. JAMA 2004;291: 210-5.

19. Schenker MP, Dorbala S, Hong CT, et al. Interrelation of coronary calcification, myocardial ischemia and outcomes in patients with intermediate likelihood of coronary artery disease: A combined positron emission tomography/computed tomography study. Circulation 2008;117:1693-700.

20. Gaemperli O, Valenta I, Schepis T, Husmann L, Scheffel H, Desbiolles L, et al. Coronary 64-slice CT angiography predicts outcome in patients with known or suspected coronary artery disease. Eur Radiol 2008;18:1162-73.

21. Boden WE, O'Rourke RA, Teo KK, Hartigan PM, Maron DJ, Kostuk WJ, et al. Optimal medical therapy with or without PCI for stable coronary disease. N Engl J Med 2007;356:1503-16.

22. Shaw LJ, Barman DS, Maron DJ, et al. Optimal medical therapy with or without percutaneous coronary intervention to reduce ischemic burden results from the Clinical Outcomes Utilizing Revascularization and Aggressive Drug Evaluation (COURAGE) trial nuclear substudy. Circulation 2008;117:1283-91. 